\title{
O Valido de \\ Beltrán de la \\ Cueva e as ligas \\ nobiliárias no \\ reinado de \\ Enrique IV (1454- \\ 1474)
}

\section{André Luis Ferreira da Rosa Junior *}

DOI: 10.11606/issn.2318-8855.v10i2p696-720

Resumo: Este artigo pretende apresentar como Beltrán de la Cueva, valido de Enrique IV na corte de Castela no século XV, foi peça fundamental de um cenário político de crise, em que os grupos nobiliárquicos que se insurgiam contra o monarca, declaravam defender a coroa do próprio rei. Portanto, uma interpretação que difere da ideia normalmente difundida pela historiografia que entende que esses levantamentos aristocráticos pretendiam o enfraquecimento da monarquia, ou seja, que seriam contra a centralização do poder régio. No caso que apresentaremos, fica evidente que a centralidade (não a centralização) do rei era importante para a nobreza, ainda que o seu poder fosse disputado por diversos grupos: uma centralidade que somente se mantinha com base em lógicas de pluralidade política. Por meio de comparações entre as crônicas escritas no período, uma favorável e outra contrária ao rei, além da leitura e análise de obras historiográficas sobre o tema, pode-se observar como as funções que o valido exercia na corte ameaçaram grupos de interesses aristocráticos, como também a reação dos afetados. O artigo procura traçar a política castelhana desde a chegada de Beltrán de la Cueva à corte, até o fim do reinado de Enrique IV, refletindo sobre as disputas da nobreza em torno do poder régio e as estratégias adotadas para preservá-lo que levaram a uma mudança na linha sucessória do trono.

Palavras-chaves: Beltrán de la Cueva; Enrique IV; Ligas nobilárias; Pluralismo jurídico; validos

* Graduando em História (Licenciatura e Bacharelado) pela Universidade de Brasília. Participa do Programa de Estudos Medievais da UnB (PEM-UnB). E-mail: andreferreirarosa1985@gmail.com 


\section{O poder na Idade Média}

O valido de Beltrán de la Cueva e as ligas nobiliárias no reinado de Enrique IV Introdução

O objetivo deste artigo é aprofundar algumas questões relativas ao papel de Beltrán de la Cueva na corte de Enrique IV em conjunto de outros personagens que a compõem, bem como contribuir para problematizar as interpretações historiográficas que muitas vezes descartam a importância política do favorito/valido em Castela, no século XV. Enrique IV de Castela, o Impotente, foi rei de Castela de 1454 até sua morte, em 1474. Durante esses 20 anos, seu reinado se destacou pelas intrigas e coalizões protagonizadas pelos nobres da corte. Tal como seu pai, Juan II, Enrique IV consolidou a presença de validos ${ }^{1}$ como membros de destaque de seu reinado. Os favoritos de maior expressão eram Juan Pacheco, marquês de Vilhena; Beltrán de la Cueva, duque de Albuquerque, e Miguel Lucas de Iranzo, condestável de Castela. Com participação ativa na maioria das decisões da corte, e muitas vezes até governando no lugar do rei, esses validos se destacaram dos demais nobres que gravitavam em torno da corte, pela sua proximidade pessoal com o rei e, supostamente, em alguns casos, com conotações amorosas. Neste trabalho, pretende-se direcionar atenção ao valido Beltrán de la Cueva, memorável pelo seu papel central nesse reinado, uma vez que se chegou mesmo a cogitar que a única herdeira biológica do monarca castelhano, Juana, seria na realidade, filha do favorito, sendo apelidada pela voz do povo como La Beltraneja.

Nascido em 1435, na cidade de Úbeda, Beltrán pertencia à linhagem de La Cueva, que concentrava bastante influência naquela região (DE BÉTHENCOURT, 1904). Seu primeiro encontro com o rei Enrique IV se deu em 1456, e de acordo com António

\footnotetext{
1 Segundo Carceller Cerviño (2009), a privança era um dos pilares fundamentais para a ascensão nas cortes castelhanas. Tida em decadência após a morte de Álvaro de Luna, a privança foi destaque no governo de Enrique IV, e seus privados gozavam de uma relação de proximidade ao rei incomparável aos demais nobres da corte e, no caso de Beltrán de la Cueva, despertando até mesmo a ira dos mesmos.
} 


\section{O poder na Idade Média}

André Luis Ferreira da Rosa Junior

Rodriguez Villa:

Dom Diego the suplicou que deixasse Juan em sua companhia, por ser o mayorazgo de sua casa, e que em seu lugar levasse seu segundo filho Beltrán, que por ser muito discreto poderia servi-lo melhor. Aceitou assim o rei [...] (RODRÍGUEZ VILLA, 1881, p. 2, tradução nossa). ${ }^{2}$

Rodríguez Villa, corroborado pelas crônicas escritas no período, mostra que a união do rei com seu valido se deu por acaso, uma vez que Enrique IV pretendia favorecer o primogênito da família La Cueva, Juan. O pai dos irmãos, então, suplicou ao rei para que deixasse o primogênito em casa e levasse seu segundo filho, Beltrán. Assim, este se tornou paje de lanza e seguiu com o rei para a corte. No entanto, sua ascensão em Castela começa efetivamente em 1457, quando é nomeado mayordomo 4 da casa de Enrique. Rodríguez Villa, amparado pela crônica de Alonso de Palencia, relata o tipo de relação que se desenvolve entre ambos:

[...] buscou em seu afável pajem, e encontrando nele sincero carinho e ardentes desejos de agradar-Ihe e distrair-lhe, ele irá enchê-lo muito em breve com as mãos cheias de honras [...]. Assim, tanto por esta razão como por contrapor o poder dos Grandes, elevou a altos cargos em 1457 a alguns de seus criados. Nomeou a Dom Beltrán como mordomo de sua casa. (RODRÍGUEZ VILLA, 1881, p. 9, tradução nossa) ${ }^{5}$

\footnotetext{
${ }^{2}$ No original: “Don Diego le suplicó tuviese á bien dejar em su compañia á Juan, por ser el mayorazgo de su casa, y que en eu lugar se llevase á su segundo hijo Beltran, que por ser muy discreto y de claro ingenio podria servirle como el mayor. Aceptoló así el Rey [...]"

${ }^{3}$ Se define, segundo o Diccionario Enciclopédico Gaspar y Roig, como o criado cujas funções eram de acompanhar seus senhores, mais especificamente no caso de Beltrán, carregar as armas do senhor quando ele as necessitava.

${ }^{4}$ Carceller Cerviño (2007) aponta que, além de mayordomo, Beltrán também foi nomeado maestresala, recebendo as mesmas quitações que recebia em seu cargo anterior (13.800 maravedís), além de contradizer a data de Rodríguez Villa, dizendo que o ocorrido se deu em 1458, um ano depois.

${ }^{5}$ No original: "[...] buscase el de su afable paje, y encontrando en él sincero cariño y ardientes deseos de agradarle y distraerle, le colmase bien pronto y á manos llenas de honores [...]. Así, tanto por esta razon como por contrarestar el poder de los Grandes, elevó á altos cargos em 1457 á algunos de sus criados. Nombró á don Beltrán mayordomo de su casa $[\ldots]^{\prime \prime}$
} 


\title{
O poder na Idade Média
}

\section{O valido de Beltrán de la Cueva e as ligas nobiliárias no reinado de Enrique IV}

Esse ofício régio, por permitir ao valido proximidade incomparável com o monarca, concedeu a Beltrán a possibilidade de interferir nos negócios do reino, como insinua Alonso de Palencia (1973, p. 272, tradução nossa) ${ }^{6:}$ : “[...] atrevendo-se a intervir nas conversas com certa confiança e graça e a tentar penetrar no que era mais reservado." Logo, o favorito do rei começou a chamar mais a atenção da corte e dos nobres mais próximos, devido a ser originário de "linhagem desconhecida e natureza corrompida" (ALONSO DE PALENCIA, 1973, p. 271, tradução nossa)7. Beltrán iniciou uma rápida ascensão na corte, não alheia às críticas da nobreza. Em 1461, efetivamente, se tornou parte do Conselho do Rei, além de receber concessões patrimoniais diversas por toda Castela. No entanto, a mira dos nobres se vira definitivamente contra Beltrán de la Cueva quando ele se torna Mestre da Ordem de Santiago, em 1464, uma nomeação contestada pelo marquês de Vilhena, Juan Pacheco, que aspirava ao cargo desde a sua vacância, em virtude da morte do condestável Álvaro de Luna. Aponta Rodríguez Villa:

\begin{abstract}
Com um desprezo tão infame, Dom Enrique com ódio maior ao Marquês de Vilhena, e mais amor e afeição pelo Conde de Ledesma, e assim, para exaltar e recompensar sua lealdade e porque ele poderia servir melhor e contrariar o Marquês, determinou nomeá-lo Mestre de Santiago, cargo que conferia tanta autoridade, poder e riqueza a quem o desempenhava, que era solicitado por todos e invejado. (RODRÍGUEZ VILLA, 1881, p. 24, tradução nossa) ${ }^{8}$
\end{abstract}

Encontra-se neste trecho um dos principais motivos que embasa a revolta de Juan Pacheco contra o rei. Ele havia sido protegido de Álvaro de Luna, e percebe-se

\footnotetext{
${ }^{6}$ No original: “[...] atreviéndose á intervenir em las conversaciones com certa confianza y gracejo y á intentar penetrar lo más reservado"

7 No original: "oscuro linage y de natural corrompido"

${ }^{8}$ No original: "Con tan infame desacato cobró Don Enrique mayor odio al partido del Marqués de Villena, y más amor y aficion al Conde de Ledesma, y así, por más enaltecerle y premiar su lealtad y porque mejor le pudiese servir y contraestar al Marqués, determino nombrarle Maestre de Santiago, cargo que conferia tanta autoridade, poder y riquezas al que lo desempeñaba, que era de todos solicitado y envidiado"
} 


\section{O poder na Idade Média}

André Luis Ferreira da Rosa Junior

que Pacheco pretendia, no reinado de Enrique $\mathrm{IV}^{9}$, conseguir ocupar as mesmas posições do antigo condestável ${ }^{10}$. Também nesse momento, iniciam-se os questionamentos em torno do verdadeiro significado de Beltrán de la Cueva para a corte, pois fica claro que o favorito do rei não estava no mesmo patamar do agora condestável Miguel Lucas de Iranzo ou do marquês de Vilhena, ambos considerados igualmente validos do rei. Assim, pode-se concluir que já em 1464, Beltrán se transformava em peça central do governo de Enrique IV, e um dos principais atores das guerras civis que marcarão os 20 anos daquele reinado. Colocam-se ainda as questões políticas decorrentes do que se considerava poder desmedido concedido a um único nobre, achegado ao rei, sendo que alguns desses cargos, territórios e direitos eram tradicionalmente divididos entre diversos senhorios do reino (CARCELLER CERVIÑN, 2007, p. 122).

A partir de então, Juan Pacheco e um de seus maiores aliados, o Arcebispo de Toledo Alonso Carillo, demonstram sua clara insatisfação com o rei, concretizando a criação de uma liga nobiliária ${ }^{11}$. Assim, pode-se começar a entender a genealogia de dois grandes acontecimentos ocorridos em Castela, no reinado de Enrique IV: A Fársa de Ávila, em 1465, e a Batalha de Olmedo, em 1467. O maior destaque relativamente a esses conflitos não se refere ao rei, seus aliados ou seus opositores, mas às diversas alianças e coalizões realizadas entre esses diversos personagens, de menor ou maior relevância para este estudo, em um jogo de poder que não finda com a morte do

\footnotetext{
${ }^{9}$ Luis Suárez Fernández, em sua obra "Historia de España: Edad Media", disserta que, no que se refere à política externa do governo de Enrique IV, Juan Pacheco seguiu à risca as decisões de Álvaro de Luna quando governou Castela (SUÁREZ FERNÁNDEZ,1970, p. 546)

10 Suárez Fernández também coloca que Juan Pacheco e seu irmão Pedro Girón se viram como beneficiários da nova situação em Castela (após a morte de Juan II), e se mostravam fiéis discípulos do "gran governante" se referindo a Álvaro de Luna (SUÁREZ FERNÁNDEZ,1970, p. 546)

${ }^{11}$ Para Manzano Moreno (2010, p.653), a liga nobiliária que se formou em torno destes grandes personagens começou a dar passos para acabar com Beltrán de la Cueva já em 1464, usando contra o Rei e seu valido acusações "genéricas e impossíveis de contestar".
} 


\section{O poder na Idade Média}

\section{O valido de Beltrán de la Cueva e as ligas nobiliárias no reinado de Enrique IV}

monarca, mas perdura também nos primeiros anos do reinado de Isabel. Essas relações apresentam uma faceta da monarquia muitas vezes ignorada pela historiografia, que é a pluralidade de forças que a compõem, o que entra diretamente em choque com o conceito tradicional de monarquia absolutista. O rei não detinha o monopólio do poder. Desde a influência de seus validos até o conflito aberto com determinados grupos de súditos, que não concordavam com suas ações e, portanto, se uniam em oposição ao monarca, mas para defender a coroa. Assim, uma historiografia que assume um modelo pré-concebido de monarquia - neste caso assentado em ideias estatistas e monopolistas de poder - acaba por descartar diversas nuances que aparecem nas ações desses personagens que explicitam um modelo de governar plural, no qual a coroa faz parte de um todo. Modelo este que é adotado por diversos historiadores, a exemplo de Luis Suárez Fernández e de Eduardo Manzano.

\section{Os validos de Enrique IV}

A realeza castelhana na Baixa Idade Média possui, para François Foronda, um duplo princípio básico: o rei há de reger e também se reger. Para que cumpra esta "obrigação dupla que define o seu reinado" (FORONDA, In: NIETO SORIA, 2006, p. 4, tradução nossa) ${ }^{12}$, o monarca deve buscar conselhos de diversas maneiras, como através da criação de um Conselho Real ou de um conjunto de nobres que se envolvem nos assuntos da coroa. No entanto, os reis em Castela, destacando-se Juan $\mathrm{II}^{13}$, atraíram a má fama de preferir outra fonte de conselhos: os validos. Estes favoritos se destacavam pela sua proximidade incomparável à coroa e influência

\footnotetext{
${ }^{12}$ No original "doble obligación que define su estado régio".

13 Que teve em sua corte o mais renomado desses validos: o condestável Álvaro de Luna. Para um maior entendimento sobre a influência do condestável no governo e na política castelhana de Juan II, ver artigo de Álvarez Palenzuela: Del gobierno de la oligarquía a la tiranía de D. Álvaro (1435-1439).
} 


\section{O poder na Idade Média |}

André Luis Ferreira da Rosa Junior

ímpar nas decisões régias, além de garantirem para si uma via de ascensão na corte que não estava à disposição dos demais. Enquanto normalmente o poder aristocrático era alcançado por nascimento em berço nobre ou através da cavalaria (BASCHET, 2006), os favoritos atingiam suas posições através de sua relação pessoal com o Rei, e muitas vezes os demais nobres questionavam a posição desses validos devido à sua falta de linhagem nobre, como foi o caso da dita "obscura linhagem" de Beltrán de la Cueva. Não se pode, então, negar o destaque que esses validos tiveram em Castela no século XV. Tendo como exemplo máximo Don Álvaro de Luna, esses personagens marcaram presença nas decisões do reino, além de possuírem territórios e direitos que aumentavam seu prestígio diante os demais.

Enrique IV teve três validos em seu reinado: Juan Pacheco, oriundo do período em que ainda era príncipe; Miguel Lucas de Iranzo, nomeado Condestável de Castela, e Beltrán de la Cueva, personagem central deste artigo. No entanto, para compreender as complexas relações entre esses personagens, se faz necessária uma introdução sobre as relações destes com o Rei e com os nobres mais próximos da corte.

\subsection{Juan Pacheco}

Sem dúvida, Juan Pacheco, o marquês de Vilhena, é um dos personagens de maior destaque da corte de Enrique IV, que já havia alcançado grande prestígio na nobreza castelhana no reinado de Juan II. Protegido desde sua chegada na corte por Álvaro de Luna, foi em 1436 que o marquês se aproximaria do então príncipe Enrique. Como paje, Pacheco se pôs ao serviço do rei e já era então considerado o "grande pri- 


\section{O poder na Idade Média}

\section{O valido de Beltrán de la Cueva e as ligas nobiliárias no reinado de Enrique IV}

vado do príncipe" (PÉREZ DE GÚZMAN, 1953, p. 607, tradução nossa) ${ }^{14}$. Assim obteve rápida ascensão na nobreza ao lado do futuro rei, aconselhando-o nas funções que Ihe cabiam, tirando partido do aprendizado que obteve de Álvaro de Luna, ${ }^{15}$ e cada vez mais se aproximando do monarca. Na crônica de Alonso de Palencia, existe um trecho que reflete bem o que Pacheco sentia por Álvaro de Luna:

As mesmas artes usou D. Juan Pacheco para levar o príncipe D. Enrique a fazer causa comum com aqueles que trabalhavam pela ruína do seu país, porque enquanto Luna participava da elevação de Don Juan Pacheco, esse preparava a vingança do valido, e não pelo efeito de afeto recíproco, mas pelo desejo comum de criar aqueles que gostariam de ver prepotentes e humilhar aqueles que desejavam abater. (ALONSO DE PALENCIA, 1973, Tomo I, p. 52, tradução nossa) $)^{16}$

No que se refere aos demais nobres da corte, Pacheco tinha forte vínculo com seu irmão, Pedro Girón, e com o Arcebispo de Toledo, Alonso Carillo. Juntos formaram, em 1464, uma liga nobiliária oposta ao rei que será responsável pela Fársa de Ávila e consequentemente irá se enfrentar ao monarca na Batalha de Olmedo.

\subsection{Miguel Lucas de Iranzo}

A ascensão de Miguel Lucas de Iranzo está diretamente ligada à guerra em Granada ${ }^{17}$, em 1455, onde serviu ao rei através de Juan Pacheco. O condestável tinha uma origem humilde, e ascendeu na corte através dos serviços prestados a Enrique

\footnotetext{
${ }^{14}$ No original: "gran privado del Príncipe"

${ }^{15}$ Carceller Cerviño aponta que Juan Pacheco foi o indutor das ações do príncipe Enrique tanto contra o Rei Juan II quanto contra o condestável Álvaro de Luna, o que é uma reprodução da crônica de Alonso de Palencia, como o trecho a seguir mostra. (CARCELLER CERVIÑO, 2009)

${ }^{16}$ No original: "Iguales artes empleó D. Juan Pacheco para arrastrar al príncipe D. Enrique á haver causa común com los que por la ruina de su pátria trabajaban, pues mientras el de Luna atendía á la elevación de don Juan Pacheco, éste preparaba la venganza del Privado, y no certamente por efecto de recíproco cariño, más por el común anhelo de levantar á los que querían ver prepotentes, y humilhar á los que deseaban dejar abatidos.

${ }^{17}$ A ofensiva contra Granada se deu após as Cortes de Cuellar, em 1455, em que, como conta a crônica de Diego Enriquez, o Rei convocou seus vassalos para uma guerra justa na região da Andalucia contra os Mouros (ENRíQUEZ DEL CASTILLO, 1994, p. 16-21). Esta foi a primeira guerra do governo de Enrique IV, e relata Alonso de Palencia que, para o monarca, o conflito teve como objetivo ganhar a graça dos nobres em um período conturbado da sucessão castelhana (ALONSO DE PALENCIA, 1953, p. 149-151).
} 


\section{O poder na Idade Média |}

André Luis Ferreira da Rosa Junior

IV. Catherine Soriano observa que, entre 1455 e 1458, o valido adquire os seguintes títulos: "Corregidor de Baeza, Alcayde de Alcalá la Real, senõr de Baños y Linares y Chanciller Mayor", além de ser nomeado "halconero mayor" de Enrique (SORIANO, 1988), o que mostra uma rápida ascensão em um curto período de tempo, precedendo a de Beltrán de La Cueva. Em 1458, após a chegada deste na corte, a disputa entre os três validos se materializa na disputa em torno do mestrado da Ordem de Santiago, cargo cobiçado por Juan Pacheco, Pedro Girón e Miguel Lucas de Iranzo. No entanto, o rei nomeia Beltrán de la Cueva, enfurecendo os demais pretendentes. Miguel Lucas, então, se afastou da corte, mas retornou em seguida, sendo forçado a fazer um juramento de que acompanharia o rei por dois meses em suas viagens, e se mostrava obrigado a honrar os benefícios que havia recebido. Ao final dos dois meses, o condestável, alegando uma lesão física, se retira para a cidade de Jaén, onde "as preocupações do Condestável eram a defesa da fronteira e a representação de sua alta dignidade em atos espetaculares" (ENRÍQUEZ DEL CASTILLO, 1998, p. 73) ${ }^{18}$. Nota-se, na historiografia, um certo silêncio sobre Lucas de Iranzo, talvez devido ao fato de seu afastamento precoce e abrupto da corte. No entanto, o destaque incide sobre o título de Condestável concedido, uma vez que antes pertencera ao prestigiado Álvaro de Luna. Observa-se também que o valido não chegou a participar das guerras civis do reinado de Enrique, pois se retirou para Jaén ainda em 1458.

\subsection{Beltrán de la Cueva}

O principal valido analisado neste estudo é Beltrán de la Cueva. Nascido em Úbeda, em 1435, ele foi alvo de muitas críticas e acusações durante o reinado de Enrique IV, sendo uma delas a da paternidade biológica de Juana, sucessora do rei e

\footnotetext{
${ }^{18}$ No original: "las preocupaciones constantes del Condestable serán la defensa de la frontera y la representación de su alta dignidad en actos espectaculares".
} 


\section{O poder na Idade Média}

\section{O valido de Beltrán de la Cueva e as ligas nobiliárias no reinado de Enrique IV}

causa de uma guerra civil em torno da legitimidade daquele monarca. Chegou à corte ao lado do rei e rapidamente ascendeu no reino até estar próximo a ele em todas as importantes decisões políticas desse período. Causou a insatisfação da nobreza que o acusava de não pertencer àquele espaço, pela sua "linhagem desconhecida". Seus principais oponentes eram Juan Pacheco e seu irmão, Pedro Girón, como também o Arcebispo de Toledo, Alfonso Carrillo, todos personagens centrais dos conflitos internos do reinado de Enrique IV. Para grande parte da historiografia, a figura de Beltrán de la Cueva não parece ter grande impacto, uma vez que é considerado "mais um valido" de uma longa lista de favoritos do rei, como apontado no trabalho de José María Soler García sobre o marquesado de Vilhena, demonstrando que para o “débil monarca castelhano", (SOLER GARCIA, 2006, p. 160, tradução nossa) ${ }^{19}$ Beltrán de la Cueva não era nada mais do que uma sombra, e sua presença na corte uma ofensa aos nobres.

De forma diversa, o objetivo deste artigo é demonstrar como Beltrán de La Cueva se torna peça fundamental da corte de Enrique e como as relações entre os nobres ajudam a ressaltar a existência de uma matriz de poder que se baseia em lógicas de pluralidade política.

Como apontou Carceller Cerviño (2006, p. 786), a nobreza manteve sua luta para alcançar posições de destaque e prestígio na corte, e a partir da chegada de Beltrán de La Cueva, aqueles que buscavam ascender deveriam passar também pelo aval do valido, o que gerou a insatisfação não somente destes como também dos que já detinham poder. Esse conflito foi uma das peças mais importantes no desenvolvimento do reinado de Enrique IV. Muito se discutiu sobre as relações de Beltrán com o rei, tanto de cunho político quanto sexual. Sobre este aspecto, destacam-se as obras

\footnotetext{
${ }^{19}$ No original: "débil monarca castellano"
} 


\section{O poder na Idade Média}

André Luis Ferreira da Rosa Junior

de Arturo Firpo, Los Reyes Sexuales, e também o Ensayo Biológico sobre Enrique IV de Castilla, de Gregório Marañon.

Arturo Firpo aponta que os valores cristãos restritivos que orientavam a sexualidade não foram impedimento para que se fizesse uso deles na política. No caso de Enrique IV, diversas acusações foram feitas sobre o rei, tanto para diminuir seu poder sobre a corte quanto para converter a opinião pública (FIRPO, 1984, p. 220). O autor discorre sobre três características de Enrique: sensível, cortesão e sexual, este último significando a publicidade de suas relações extraconjugais (FIRPO, 1984, p.227). Dessa maneira, suas relações tanto com as meretrizes de Segóvia quanto com os privados de sua corte se tornam debate público e arma da oposição. Gregório Marañon se aprofunda na questão da impotência do monarca, abordando suas relações com os validos. Entretanto, para este autor, a questão da infidelidade de sua esposa, Joana de Portugal, com Beltrán, que se especula ter resultado na gravidez da infanta Juana, não merece credulidade (MARAÑON, 2000, p. 93). Para ele, Enrique apresentava uma impotência parcial, que não o impossibilitava de manter relações sexuais e produzir herdeiros. Diz Marañon que:

"[...] deve ter sofrido de uma impotência parcial. Como ocorre a esses indivíduos, foi, sem dúvidas, um tímido sexual, propenso à incapacidade absoluta, por motivos psicológicos, com certas mulheres, sobretudo com as de maior prestígio social. Tal ocorreu, sem dúvida, com sua primeira mulher, dona Blanca de Navarra". MARAÑON, 2000, p. 92 e 93, tradução nossa)." 20

A herdeira de Enrique, Juana, ficou conhecida como "La Beltraneja" (SITGES, 1902, p. 234), pela desconfiança de ser Beltrán de la Cueva o verdadeiro progenitor, estimulando a insatisfação da corte com o monarca e seu valido. A suposta ilegitimidade de Juana influenciou a liga nobiliar de Juan Pacheco a fomentar a ascensão de D.

\footnotetext{
${ }^{20}$ No original: "[...] como les ocurre a estos individuos, fue, sin duda, un tímido sexual, propenso a la incapacidad absoluta, por motivos psíquicos, con ciertas mujeres, sobre todo con las de mayor diferenciación social. Tal ocurrió, sin duda, con su primera mujer, doña Blanca de Navarra."
} 


\section{O poder na Idade Média}

\section{O valido de Beltrán de la Cueva e as ligas nobiliárias no reinado de Enrique IV}

Alfonso, irmão do rei, ao trono, e, posteriormente, Isabel, a Católica, também se utilizou desse rumor para legitimar sua pretensão à coroa de Castela.

\section{A influência de Beltrán na corte}

Para entender a influência que detinha Beltrán de la Cueva na corte de Enrique IV, é preciso primeiramente entender a situação política do reinado em 1456, quando o valido chega à corte. Para o cronista Diego Enríquez del Castillo, os primeiros anos do governo de Enrique foram tranquilos (ENRÍQUEZ DEL CASTILLO, 1994, pp. 22 e 23), enquanto para Alonso de Palencia (1973, Tomo I, p. 176), nem tanto ${ }^{21}$. As duas crônicas relatam, de maneira distinta, a guerra de Castela contra os mouros em Granada, em 1455. Para Castillo, o rei era:

[...] piedoso, e não cruel, mais amigo da vida dos seus do que do derramamento de seu sangue, dizia: que então a vida dos homens não tinha preço nem equivalência; era um erro muito grande consentir em aventurá-la. (ENRÍQUEZ DEL CASTILLO, 1994, p. 23, tradução nossa) 22

Já para Palencia, o rei fingia sentimentos de bondade ao afirmar que a empreitada contra os mouros em Granada foi "uma conduta vergonhosa de D. Enrique"

\footnotetext{
${ }^{21}$ É importante discutir a cronística sobre Enrique IV. Suas duas crônicas principais, estudadas aqui, foram escritas em momentos distintos. Diego Enríquez de Castillo produziu sua narrativa na condição de cronista régio. No entanto, como nos conta Gomez Redondo (2007, p. 3481) esta foi roubada e entregue a Alonso de Palencia, cronista partidário de Juan Pacheco e Isabel, para que "denunciasse suas falsidades". Desta segunda crônica, escrita em latim, surge uma terceira crônica, anônima, que é utilizada como base por Diego de Valera, já durante o reinado dos Reis Católicos, para redigir uma quarta crônica sobre Enrique IV, dessa vez estabelecendo uma "visão histórica dos monarcas a quem serve" (GÓMEZ REDONDO, 2007, p. 3481). Jaume Aurell (2016) critica o juízo simplista que concebeu a imagem do historiador medieval como mero compilador e estático observador da realidade, destituído de racionalidade, e ao analisar e confrontar essas crônicas, podemos perceber que existem diferentes narrativas, sobre os mesmos acontecimentos, constituindo versões que favorecem o autor do texto e/ou aquele que o encomendou.

${ }^{22}$ No original: "[...] piadoso, é no cruel, mas amigo de la vida de los suyos, que derramador de su sangre, decia: que pues la vida de los hombres no tenia prescio, ni avia equivalência, que era muy grand yerro consentir aventuralla."
} 


\section{O poder na Idade Média}

André Luis Ferreira da Rosa Junior

(ALONSO DE PALENCIA, 1973, Tomo I, p. 176, tradução nossa) ${ }^{23}$. Sabe-se que a guerra era uma das principais maneiras da nobreza demonstrar seu valor, e a reação de Enrique não valorizava esse aspecto. O rei adotou uma estratégia de enfraquecimento econômico do inimigo, queimando plantações e cercando as fronteiras de Granada, o que, segundo Palencia, deixou os nobres insatisfeitos. Ao mesmo tempo, como já referido, a contínua presença dos validos na corte impedia que grupos importantes da nobreza tivessem acesso à distribuição de benefícios régios, diminuindo, assim, o prestígio daqueles que se sentiam prejudicados.

Em 1456, Beltrán de la Cueva começa sua carreira como pajem na corte, tornando-se logo mordomo, em 1458. Percebe-se nessa rápida ascensão que Beltrán se destacou não só politicamente, como militarmente, ao lado de Enrique IV. O ofício do mordomo representava a proximidade com o rei, por possibilitar que Beltrán interferisse diretamente nos assuntos da corte, e circular livremente nos aposentos régios. Além da aquisição de extenso patrimônio em Castela, a maior demonstração da influência de Beltrán de la Cueva na corte se evidencia em 1460, quando é nomeado para o Consejo del Rey, com a "capacidade de intervir nos assuntos de Estado de uma forma direta, ainda que temperada naturalmente pela vontade régia [...]" (CARCELLER CERVIÑO, 2006, p. 119) ${ }^{24}$. Neste mesmo ano, Enrique IV concede a Beltrán de la Cueva o território de Andrada, pertencente à família de Álvaro de Luna, a qual não aceitava a autoridade do rei após a morte do condestável.

Esses territórios representavam mercês de grande influência na Idade Média, principalmente aqueles pertencentes ao favorito de Juan II, devido ao poder que Álvaro de Luna detivera em Castela. É importante notar também que Juan Pacheco, o

\footnotetext{
${ }^{23}$ No original: "una conducta vergonhosa de D. Enrique"

24 No original: "capacidad para intervenir en los asuntos de Estado de una forma directa, aunque matizada naturalmente por la voluntad regia [...]"
} 


\section{O poder na Idade Média}

O valido de Beltrán de la Cueva e as ligas nobiliárias no reinado de Enrique IV marquês de Vilhena, havia se casado com Angelina de Luna (CARCELLER CERVIÑO, 2009, p. 97) anos antes do início do reinado de Enrique IV, bem como servido a Álvaro de Luna antes da trágica morte do condestável.

Com grande influência na corte, Beltrán não se esqueceu de sua família. Antonio Rodríguez Villa conta em seu Bosquejo Historiografico de Beltrán de la Cueva que o valido nomeou - por intermédio do rei - seu irmão Gutierre de la Cueva como bispo de Palencia e conde de Pernia (RODRíGUEZ VILLA, 1881, p. 10). À luz desses fatos, observa-se que a influência de Beltrán na corte era inigualável. O valido conseguiu ascender de forma ímpar durante o reinado de Enrique IV, resultando em seu casamento com Mencía, da família Mendoza, uma das mais influentes famílias de Castela, além de se ter tornado membro do Consejo del Rey. O favorito é sem dúvidas um personagem incontornável na história do reinado de Enrique IV.

Deve-se mencionar também, além das questões políticas e econômicas, a proximidade do rei com seu valido em outros aspectos. Desde que chegou à corte em 1456, corriam rumores sobre uma suposta relação amorosa entre Beltrán de la Cueva e Enrique IV. No entanto, foi com o nascimento de Juana, filha de Enrique com a rainha Joana, que os rumores adquiriram proporções escandalosas. Beltrán era, para o povo, amante tanto do rei quanto da Rainha, e não demorou muito para que a paternidade de Juana fosse atribuída ao valido. Devido aos problemas do rei em gerar herdeiros, Juana ficou conhecida como "la Beltraneja", em clara referência à sua suposta filiação ao favorito do rei. No livro de Manzano Moreno, sobre a história da Espanha, há um poema que explicita a opinião do povo sobre a presença de Beltrán de la Cueva na corte (MANZANO MORENO, 2010, p. 653):

"Y es publica voz y fama 


\title{
O poder na Idade Média
}

André Luis Ferreira da Rosa Junior

\author{
Que odiste personas tres, \\ à tu amo y à tu ama \\ Y à la hija del marqués. \\ Odes al Rey y à la Reina, \\ odes las tres Badajozes; \\ $Y$ todo el mundo se espanta \\ Como no odes à la Infanta"
}

A composição, embora sem citar nomes, refere-se claramente ao valido do rei, Beltrán de la Cueva, que após o nascimento da herdeira do trono Juana, em 1462, foi acusado de ser o genitor da princesa. Após as diversas especulações sobre a potência sexual do rei, e até mesmo sobre sua sexualidade, com a gravidez da Rainha começaram os rumores de que a paternidade devia ser atribuída a Beltrán, o homem mais próximo ao rei. O poema também remete às filhas da família Badajoz, a esposa de Beltrán, filha do marquês de Santillana, bem como à Infanta Isabel, futura rainha. Percebe-se, a partir dessa composição, que a imagem pública tanto do rei quanto de sua corte estava prejudicada no imaginário do povo (CARRASCO MANCHADO, 2001).

\section{Conflito Sucessório}

Desde o nascimento de Juana, multiplicaram-se as tensões na corte. Como a opinião pública difundia o rumor sobre a paternidade da princesa, alguns nobres, já insatisfeitos com o rei, formaram as famosas ligas nobiliares, que acabaram por se tornar em uma das principais características do cenário político castelhano do século $X V$. Por uma teia de relações fluídas e sempre adaptáveis, as ligas definiram conflitos e até mesmo coroaram novos reis. As duas ligas principais para se entender o conflito sucessório que resultou no fim do reinado de Enrique IV foram as constituídas por Juan Pacheco e seu irmão, Pedro Girón, e a formada por Beltrán de la Cueva, Enrique IV e a família Mendoza. Antes é necessário, porém, discorrer sobre o peso das disputas em torno do mestrado da Ordem de Santiago. 


\section{O poder na Idade Média}

\section{O valido de Beltrán de la Cueva e as ligas nobiliárias no reinado de Enrique IV}

\subsection{O Maestrazgo de Santiago}

Com a coroação de Enrique IV, em 1454, também Ihe foi concedido o título de Mestre de Santiago, um cargo diferenciado se comparado às demais mercês régias de Castela. Pedro Arboledas, em sua tese de doutorado, explora os aspectos políticos, econômicos, demográficos e sociais que abrangiam a Ordem de Santiago (ARBOLEDAS, 1997).

A Ordem possuía um importante papel principalmente na política de Castela, sendo uma mercê de grande prestígio e cobiçada por todos os nobres da corte. Durante o reinado de Juan II, o título de mestre foi cedido a Álvaro de Luna, o condestável de Castela, que só vagou com sua morte, em 1453. Logo em seguida, o rei Enrique se torna mestre, até que seu irmão, D. Alfonso, alcançasse a maioridade para assumir o cargo (ARBOLEDAS, 1997, p. 26). No entanto, em 1462, Enrique IV nomeia seu valido, Beltrán de la Cueva, como maestre da Ordem, enfurecendo os nobres da corte, principalmente Juan Pacheco, que desejava o título para si. Arboledas discorre brevemente sobre a decisão de Enrique IV de nomear Beltrán como mestre:

O motivo do rei Enrique enobrecer a Dom Beltrán reside na falta de apoio nobiliárquico à sua pessoa; nesta linha, renunciou à administração da Ordem de Santiago ao papa, pedindo-lhe para investir a seu vassalo, feito que irritou muito a Dom Juan Pacheco, marquês de Vilhena e os condes de Alba e Benavente, entre outros, que tomaram bandeira a favor do Infante dom Alfonso (ARBOLEDAS, 1997, p. 152, tradução nossa) ${ }^{25}$

O autor trata da perda de apoio da nobreza sofrida por Enrique IV, decorrente

\footnotetext{
${ }^{25}$ No original: "La causa de que el Rey Enrique ennobleciese a don Beltrán está en la falta de apoyo nobiliario a su persona; en esta línea, renunció la administración de la Orden de Santiago en el papa, rogándole proveyera a su vasalo, hecho consumado que enfadó mucho a don Juan Pacheco, marqués de Villena, y a los condes de Alba y Benavente, entre otros, que levantaron bandera a favor del Infante don Alfonso."
} 


\section{O poder na Idade Média}

André Luis Ferreira da Rosa Junior

do nascimento de sua filha Juana, como também dos privilégios cedidos a Beltrán de la Cueva em detrimento dos demais nobres da corte. Neste momento, em 1462, Miguel Lucas de Iranzo já estava afastado do centro do poder, tendo retornado para Jaén, apesar de manter o título de Condestável de Castela. É Juan Pacheco que se volta contra o rei em uma tentativa de enfraquecer o poder real a favor de Dom Alfonso, que mais tarde Pacheco chamaria de rei.

As vantagens do mestrado de Santiago são explicas por Arboledas:

[...] o mestre, movendo o mutável, detinha dentro do instituto um papel certamente parecido ao de um monarca em seu reino, com a vantagem de ser, ao mesmo tempo, chefe espiritual de seus freires. (ARBOLEDAS, 1997, p. 152, tradução nossa) ${ }^{26}$

Comparar a influência do mestre à de um monarca certamente não é inapropriada. A Ordem de Santiago abrangia todo o noroeste de Leão e Castela, bem como de parte de Portugal, o conhecido Caminho de Santiago. A nomeação de Beltrán para o cargo de mestre foi o ápice da insatisfação da nobreza com Enrique IV, e a partir desse momento se inicia uma articulação para destroná-lo.

\subsection{As ligas nobiliárias}

As ligas nobiliárias "são pactos coletivos, de nobres unidos por uma causa comum, que se levantam e tratam de impor suas regras ao monarca e ao grupo que Ihes é fiel" (CARCELLER CERVIÑO, 2006, p. 609, tradução nossa). ${ }^{27}$ Após a nomeação de Beltrán, firma-se um pacto entre Juan Pacheco, seu irmão, Pedro Girón, e o Arcebispo de Toledo, Alfonso Carillo, justamente para questionar esta decisão de Enrique IV. Esse grupo, em um irrefutável ato político, que claramente demonstra um

\footnotetext{
${ }^{26}$ No original: "[...] el maestre, mudando lo mudable, jugaba dentro del instituto un papel certamente parecido al del monarca en su reino, con la ventaja de ser, al propio tempo, jefe espiritual de sus freires."

${ }^{27}$ No original: "Son pactos colectivos, de nobles unidos por una causa común que se levantan y tratan de imponer sus reglas al monarca y al grupo que le es fiel"
} 


\section{O poder na Idade Média}

\section{O valido de Beltrán de la Cueva e as ligas nobiliárias no reinado de Enrique IV}

interesse e um programa político, contrariam o ato de Enrique IV e se declaram inimigos de Beltrán de la Cueva. Um dos primeiros movimentos do grupo foi tentar apoderar-se da cidade de Úbeda, cidade natal de Beltrán, devidamente defendida pela família la Cueva e por Miguel Lucas de Iranzo, que manteve seu apoio ao favorito e ao rei.

Por outro lado, formou-se um grupo favorável a Beltrán, composto principalmente pelo monarca inglês, Eduardo IV, e o rei português, Afonso $\mathrm{V}$ (CARCELLER CERVIÑO, 2006, p. 611), além do próprio Enrique IV e da família Mendoza, representada principalmente por Diego Hurtado de Mendoza, marquês de Santillana. Durante o conflito, que acabou por tomar um caráter sucessório, esses dois grupos não sofrem mudanças significativas em suas composições, mantendo os principais personagens. No entanto, é interessante notar como as relações de parentesco e de clientelismo se fazem presentes nesses grupos. Ambos possuíam agendas próprias e buscaram apoios de outros grupos, às vezes até sem interesses comuns aparentes.

\subsection{A Farsa de Ávila}

A primeira manifestação pública da insatisfação dos nobres com o rei e dos planos de coroar Dom Alfonso ocorreu na cidade de Ávila, em 5 de junho de 1464. O evento que ficou conhecido como Fársa de Ávila foi a evidência de que os planos políticos dos nobres haviam ganhado materialidade. Assim conta a crônica de Diego Enríquez del Castillo:

Logo após o fim do ato com a estátua, os bons servos do rei, agradecendo as mercês que receberam dele, levaram o príncipe Don Alonso ao topo da sepultura. Onde eles, e os outros Prelados e cavaleiros, erguendo-o sobre seus ombros e braços, com vozes muito altas disseram, Castela pelo rei Don Alonso. 


\section{O poder na Idade Média}

André Luis Ferreira da Rosa Junior

(ENRÍQUEZ DEL CASTILLO, 1994, p. 130, tradução nossa) ${ }^{28}$

Neste trecho, podemos destacar alguns pontos importantes e que refletem o acontecimento como um todo. Primeiramente, o "ato com a estátua" a que se refere o cronista é o evento em que os nobres se utilizaram de um boneco (efígie) para representar o rei Enrique $\mathrm{IV}^{29}$, sentado em um trono, com uma coroa na cabeça, o qual seria despojado de suas insígnias régias pelos nobres revoltosos que as entregaram a Dom Alfonso, irmão do Rei. Para Shima Ohara, este gesto de destronar o boneco "está baseado na ideologia teológica de Tomás de Aquino que defende que no caso de que falhe a revolta, há que matar o tirano para libertar o reino" (OHARA, 2004, p. 380, tradução nossa). ${ }^{30}$ Logo, infere-se que o ato de destronar o boneco significou, para os nobres, a liberação do reino da tirania de Enrique IV e o início de um novo reino sob a tutela de "Don Alfonso XII". Em segundo lugar, vê-se que o ato de nomear Alfonso rei se dá como um "agradecimento às mercês que receberam", mais uma vez trazendo à tona as relações de serviço e benefício que se perpetuavam nessas redes de poder em Castela no século XV. É importante destacar que essas redes de poder se ancoravam à coroa a todo momento. Com este ato, parte da nobreza defendia o poder monárquico que, para ela, havia sido enfraquecido pelas decisões tomadas por Enrique, que deslegitimava, ao mesmo tempo, a coroa e os privilégios da própria nobreza.

Angus MacKay (1985) aponta que os nobres buscavam, por meio da Farsa, a aclamação da respublica, e o papel do público era de extrema importância. Da mesma

\footnotetext{
${ }^{28}$ No original: "Luego que el abto de la estátua fue acabado, aquellos Buenos criados del Rey, agradesciendo las mercedes que de él rescibieron, llebaron al Príncipe Don Alonso hasta encima del cadahalso. Donde ellos, é los otros Perlados é caballeros, alzandolo sobre sus hombros é brazos, con voces muy altas dixeron, Castilla por el Rey Don Alonso"

${ }^{29}$ Similar a como a Inquisição na Espanha punia as efígies de hereges que haviam morrido ou fugido da prisão (MACKAY, 1985, p. 15)

${ }^{30}$ No original: "está basada en la ideología teológica de Tomás de Aquino que sostiene que en el caso de que falle la revuelta, hay que matar al tirano para liberar el reino."
} 


\section{O poder na Idade Média}

\section{O valido de Beltrán de la Cueva e as ligas nobiliárias no reinado de Enrique IV}

maneira que aconteceria com Isabel em 1474, a decisão da escolha do rei Alfonso foi tomada por um grupo de nobres, mas era necessário que a população estivesse de acordo e apoiasse o novo rei. Destacando a ilegitimidade de Juana e a ineficiência do rei Enrique em cumprir suas funções de monarca, preferindo delegá-las a seu valido, na Farsa de Ávila os nobres defendiam tanto interesses gerais quanto particulares. Estavam presentes nobres como Juan Pacheco, Alfonso Carillo, entre outros. Estes, que já haviam declarado sua insatisfação com o rei e formado uma liga nobiliária, fizeram o primeiro ato em direta oposição ao rei. Logo ao saber dos eventos que se passaram em Ávila, Enrique IV reuniu seus homens e se encontrou com Beltrán para marchar em direção a Ledesma. Infrutíferos resultados tiveram essa marcha, e Enrique e Beltrán se viram em uma Castela politicamente dividida, com uma corte enfraquecida, um ambiente perfeito para um conflito militar, que se concretizou na Batalha de Olmedo.

\subsection{A Batalha de Olmedo}

Reuniram-se em Segóvia Enrique IV e seus aliados. Como aponta Carceller Cerviño, "é evidente que os aliados de Dom Enrique queriam controlar as decisões do monarca a fim de evitar novos equívocos e manejarem a situação" (CARCELLER CERVIÑO, 2006, p. 223, tradução nossa) ${ }^{31}$. Percebe-se que mesmo entre seus aliados o monarca já não detinha tanto poder quanto no começo do reinado. É importante notar que Enrique nunca deteve o monopólio do poder, governando sempre com os seus nobres. No entanto, nesse momento, é evidente a dificuldade do rei em atrair nobres que o sustentem. As duas ligas tomam posições distintas e ficam conhecidas por alfonsinos e enriqueños. Ambas disputaram áreas de influência em Castela,

\footnotetext{
${ }^{31}$ No original: "Es evidente que los aliados de don Enrique querían controlar las decisiones del monarca a fin de evitar nuevas equivocaciones y de manejar ellos mismos la situación"
} 


\section{O poder na Idade Média}

André Luis Ferreira da Rosa Junior

buscando mais apoio e homens para uma eventual guerra, que acabaria por ocorrer nos arredores de Olmedo.

As crônicas de Alonso de Palencia e de Diego Enríquez del Castillo relatam a Batalha de Olmedo de maneira distinta. O primeiro, apoiador dos alfonsinos, destaca a movimentação das tropas de Dom Alfonso, a quem chama de rei (ALONSO DE PALENCIA, 1973, Tomo II, p. 215-222) enquanto Diego Enríquez, cronista oficial de Enrique IV, relata o lado do monarca (ENRÍQUEZ DEL CASTILLO, 1994, p. 178-188). Destacam-se trechos dessas crônicas sobre o desfecho da Batalha de Olmedo. De acordo com Palencia:

As cidades souberam o resultado da batalha com diversidade, porque ambos os lados reivindicavam vitória e os mensageiros traziam notícias diferentes; mas o que deixo referido é o verdadeiro, livre de qualquer influência de paixão ou ódio. (ALONSO DE PALENCIA, 1973, Tomo II, p. 73, tradução nossa) ${ }^{32}$

Palencia destaca que, embora os dois lados se declarassem vencedores do conflito para determinar a quem pertencia a coroa de Castela, ele, que se propõe a relatar a verdade "livre de toda influência", esclarece que Juan Pacheco, a quem chamou de Mestre de Santiago, era o lado vencedor. Diego Enríquez del Castillo, no entanto, tem uma visão diferente do ocorrido, assentada no fato de se declarar testemunha ocular dos acontecimentos. Em conversa com o próprio Enrique IV, narra:

Ande aqui, Senhor, que você é vitorioso, e que seus inimigos estão derrotados e destruídos. E quando o rei ouviu o que ele disse, com alegres risadas, ele me disse: cronista, se você com tão sãs ideias como as suas, me aconselhará [...] (ENRÍQUEZ DEL CASTILLO, 1994, p. 187, tradução nossa) ${ }^{33}$

\footnotetext{
32 No original: "Las ciudades supieron com diversidad el resultado de la batalla, porque ambas partes se atribuían la victoria y los mensajeros llevaban noticias diferentes; mas lo que dejo referido es la verdad, libre de toda influencia de pasión ó de odio."

${ }^{33}$ No original: "Andada cá Señor, que soys vencedor, é vuestros enemigos quedan vencidos, é destruídos. E quando el Rey oyó lo que asi le descia, con alegre risa me dixo: Coronista, si con tan sanas entrañas como las vuestras me aconsejara"
} 


\section{O poder na Idade Média}

\section{O valido de Beltrán de la Cueva e as ligas nobiliárias no reinado de Enrique IV}

Enríquez del Castillo atesta estar ao lado do rei ao fim da batalha de aconselháIo, o que Ihe dá autoridade para dizer quem venceu. No entanto, o consenso historiográfico é que não houve vencedor claro da batalha, ainda que as baixas tenham sido maiores do lado dos alfonsinos. De todas formas, é evidente que o rei saiu enfraquecido do confronto. Portanto, em um acordo celebrado após a batalha entre Juan Pacheco e Enrique IV, o valido Beltrán de la Cueva renunciou ao maestrazgo de Santiago em troca da renúncia de Dom Alfonso à coroa. O marquês de Vilhena, finalmente, tornou-se mestre da Ordem de Santiago. Entretanto, o ato acabou por não se concretizar, pois dependia de aprovação papal, que foi rejeitada por Antonio de Veneris, legado pontifício, que condenava as ações dos rebeldes contra Enrique IV (CARCELLER CERVIÑO, 2006, p. 226). O ocorrido gerou uma última ação por parte dos rebeldes, que ainda buscavam a queda de Enrique, agravada após a precoce morte do infante Alfonso, em 1468. A partir desse momento, os rebeldes se voltam para Isabel, irmã do rei, como potencial herdeira da coroa de Castela.

\section{Conclusão}

Com o desfecho da batalha de Olmedo e o crescente apoio dos nobres à coroação de Isabel, a força política de Enrique IV, já frágil, ficou realmente comprometida. O rei assinou, então, o Tratado de Toros de Guisando, em 1468 (MANZANO MORENO, 2010, p. 636), declarando sua irmã a legítima herdeira, e deslegitimando, consequentemente, sua filha, Juana. Tal pacto implicou ao mesmo tempo em admitir a bastardia de Juana, em troca de se manter no trono, o que agradava a força nobiliárquica que se the opunha. Aqui percebe-se também a importância política que Isabel já detinha nessa época. Após a assinatura do Tratado, rumores de que Isabel estivesse prometida a Fernando de Aragão começaram a 


\section{O poder na Idade Média}

André Luis Ferreira da Rosa Junior

circular pela corte, e em um ato de últimas circunstâncias, Enrique IV anulou o acordo, declarando novamente sua filha Juana como legítima herdeira e realimentando o conflito sucessório que parecia resolvido. Nos anos seguintes, desencadeou-se a Guerra de Sucessão Castelhana, que durou até 1479, cinco anos após a morte de Enrique IV, com a coroação de Isabel como rainha de Castela. Em um conflito entre "Isabelinos" e "Juanistas", diversas ligas nobiliárquicas declararam seu apoio tanto a Isabel quanto a Juana, e o enfrentamento resolveu-se com a assinatura de um tratado de paz e a consolidação da primeira como legítima herdeira ao trono.

O panorama político de Castela no século XV evidencia que os agentes políticos se movem por meio de relações de parentesco e de dependência baseadas em lógicas de serviço e benefício. A importância de Beltrán de la Cueva na corte de Enrique IV explica-se por diversos motivos, mas principalmente por sua posição enfrentada a certos nobres, que aspiravam a esse mesmo poder e cargo. As reações deste grupo diante das ações do rei e de seu valido mostram que o objetivo dos nobres revoltosos, em primeiro plano, era a defesa de seus próprios privilégios, os quais dependiam da manutenção do poder régio. Portanto, seus atos, ao contrário de evidenciarem a intenção de se oporem à monarquia, mostram que eles desejavam o seu fortalecimento. Nesse sentido, Enrique IV e o valido, para eles, representavam uma ameaça à imagem da realeza e um empecilho à "justa" distribuição dos benefícios no cenário da corte. Portanto, falar em um poder plural implica em questionar a interpretação que muitas vezes se faz relativamente à posição dos nobres, que oscilaria entre meros coadjuvantes e opositores da monarquia. Ou seja, uma força que necessitaria ser eliminada ou submetida para que a monarquia pudesse exercer seu papel de acordo com o modelo. No caso das revoltas nobiliares contra Enrique IV, é possível observar que o discurso que justifica as ações está 


\section{O poder na Idade Média}

O valido de Beltrán de la Cueva e as ligas nobiliárias no reinado de Enrique IV embasado em uma lógica de tipo plural, que coloca os nobres como defensores da monarquia ideal da qual eles também se sentem parte.

\section{Referências Bibliográficas}

ALONSO DE PALENCIA. Crónica de Enrique IV, Intr. de A. Paz y Melia, BAE, vols. I - IV Madrid,1973.

ARBOLEDAS, Pedro Andrés Porras. La Orden de Santiago en el siglo XV, Madrid: Dynkinson, 1997.

AURELL, Jaume. La historiografía medieval. Entre la historia y la historiografía. Vanlencia: Univ. de Valencia, 2016.

BASCHET, Jérôme. A civilização feudal: Do ano mil à colonização da América. Tradução de Marcelo Rede - São Paulo: Globo, 2006.

CARRASCO MANCHADO, A. I. Enrique IV de Castilla. Esbozo de una representación de la propaganda política. Orientaciones. Revista de Homosexualidades, Madrid, n. 2, 2001.

CARCELLER CERVIÑO, María del Pilar. Álvaro de Luna, Juan Pacheco y Beltrán de la Cueva: un estudio comparativo del privado regio a fines de la Edad Media. En la España Medieval, v. 32, p. 85, 2009.

Realidad y representación de la nobleza castellana del siglo XV el linaje de la Cueva y la casa ducal de Alburquerque. Universidad Complutense de Madrid: Servicio de Publicaciones, 2007.

DE BÉTHENCOURT, Francisco Fernández. Historia genealógica y heráldica de la monarquía española: Casa Real y Grandes de España. Tomos I - X. E. Teodoro, 1904.

Diccionario enciclopédico de la lengua española: con todas las voces, frases, refranes y locuciones usadas en España y las Américas españolas...; por una sociedad de personas especiales en las letras, las ciencias y las artes: Augusto Ulloa... et al.; revisado por Domingo Fontan [et al.]; ordenado por Nemesio Fernández Cuesta, Madrid : Imprenta y Librería de Gaspar y Roig, 1853

ENRÍQUEZ DEL CASTILLO, Diego. Cronica del Rey D. Enrique El Quarto, Intr. de Aureliano Sanchéz Martín, vol. único Madrid, 1994. 


\section{O poder na Idade Média}

André Luis Ferreira da Rosa Junior

FIRPO, R. A. Los reyes sexuales. Ensayo sobre el discurso sexual durante el reinado de Enrique IV de Trastámara, 1454-1474. Melánges de la Casa de Velázquez. Madrid, t. 20, 1984.

FORONDA, François. La privanza, entre monarquía y nobleza. In: NIETO SORIA, José Manuel (dir.), La monarquía como conflicto en la Corona castellano-leonesa (c. 1230-1504), Madrid: Sílex, 2006, p. 73-132

GOMEZ REDONDO, F. Historia de la prosa medieval castellana. El reinado de Enrique IV. El final de la Edad Media. Madrid: Ed. Cátedra, 2007.

MACKAY, A. Ritual and propaganda in fifteenth-century Castile. Past and Present, $\mathrm{n}$. 107, p. 3-43, 1985

MANZANO MORENO, Eduardo. Historia de España. Épocas Medievales: vol. 2, Barcelona: Editorial Critica, 2010.

MARAÑON, Gregório. Ensayo biológico sobre Enrique IV de Castilla y su tiempo. Barcelona: S.L.U Espasa Libros, 2000.

OHARA, Shima. La propaganda política em torno al conflito sucessório de Enrique IV (1457-1474). Biblioteca Miguel de Cervantes, 2004.

PÉREZ DE GUZMÁN, Fernán. Crónica del Serenísimo Príncipe Don Juan, segundo rey de este nombre en Castilla y en León. Rosell (ed. y notas), Madrid: Ediciones Atlas, 1953.

RODRÍGUEZ VILLA, Antonio. Bosquejo historiográfico de don Beltrán de la Cueva, primer duque de Albuquerque, Madrid: Luis Navarro Editor, 1881.

SOLER GARCIA, José Maria. Historia de Villena: desde la Prehistoria hasta el siglo XVIII, Alicante: Biblioteca Virtual Miguel de Cervantes, 2006.

SORIANO, Catherine. El exilio voluntario de un Condestable de Castilla, Miguel Lucas de Iranzo. 1616: Anuario de la Sociedad Española de Literatura General y Comparada, n. 6, p. 71-76, 1988.

SUÁREZ FERNÁNDEZ, Luis. Historia de España: Edad Media, Madrid: Editorial Gredos S.A, 1970. 